\title{
Mitochondrial dysfunction and pancreatic islet $\beta$-cell failure (Review)
}

\author{
WENXIN SHA, FEI HU and SHIZHONG BU \\ Diabetes Research Center, School of Medicine, Ningbo University, Ningbo, Zhejiang 315211, P.R. China
}

Received February 18, 2020; Accepted July 17, 2020

DOI: $10.3892 /$ etm.2020.9396

\begin{abstract}
Pancreatic $\beta$-cells are the only source of insulin in humans. Mitochondria uses pyruvate to produce ATP as an intermediate link between glucose intake and insulin secretion in $\beta$-cells, in a process known as glucose-stimulated insulin secretion (GSIS). Previous studies have demonstrated that GSIS is negatively regulated by various factors in the mitochondria, including tRNA ${ }^{\text {Leu }}$ mutations, high p58 expression, reduced nicotinamide nucleotide transhydrogenase activity, abnormal levels of uncoupling proteins and reduced expression levels of transcription factors A, B1 and B2. Additionally, oxidative stress damages mitochondria and impairs antioxidant defense mechanisms, leading to the increased production of reactive oxygen species, which induces $\beta$-cell dysfunction. Inflammation in islets can also damage $\beta$-cell physiology. Inflammatory cytokines trigger the release of cytochrome $c$ from the mitochondria via the $\mathrm{NF}-\kappa \mathrm{B}$ pathway. The present review examined the potential factors underlying mitochondrial dysfunction and their association with islet $\beta$-cell failure, which may offer novel insights regarding future strategies for the preservation of mitochondrial function and enhancement of antioxidant activity for individuals with diabetes mellitus.
\end{abstract}

\section{Contents}

1. Introduction

2. Mitochondrial dysfunction

3. Association between mitochondrial dysfunction and islet $\beta$-cell failure

4. Conclusion

\section{Introduction}

Diabetes mellitus (DM), is a chronic endocrine disease that is characterized by peripheral insulin resistance and eventual

Correspondence to: Professor Shizhong Bu, Diabetes Research Center, School of Medicine, Ningbo University, 818 Fenghua Road, Ningbo, Zhejiang 315211, P.R. China

E-mail: bushizhong@nbu.edu.cn

Key words: mitochondrial dysfunction, diabetes mellitus, islet $\beta$-cell, reactive oxygen species, uncoupling proteins pancreatic islet $\beta$-cell failure, which poses a major threat to public health (1). The pancreas consists of endocrine glands surrounded by exocrine glands. $\beta$-cells are located within the pancreatic endocrine section, which comprise $\sim 1.5 \%$ total pancreatic volume (2). Pancreatic endocrine glands, also called pancreatic islets, mainly contain four types of cells: $\alpha, \beta, \delta$ and pancreatic polypeptide cells (3). $\beta$-cells comprise $\sim 54 \%$ of endocrine pancreatic cells and are the sole source of insulin in the body (Fig. 1) $(3,4)$. In total, 425 million people have been diagnosed with DM worldwide (2017) (5) and $>90 \%$ of DM were type 2 DM in the UK (2015) (6). The primary causes of DM-associated mortality involve complications leading to cardiovascular disease, diabetic retinopathy, nephropathy, neuropathy and lower extremity amputation $(7,8)$.

The pathogenesis of DM involves numerous genetic and environmental factors. Over the past decade, the role of mitochondria in DM has been extensively investigated $(7,9,10)$. Mitochondria serve roles in diverse cellular signaling and metabolic pathways in addition to producing ATP (11). During the process of insulin secretion, ATP generated from oxidative phosphorylation (OXPHOS) contributes to the closure of ATP-sensitive $\mathrm{K}^{+}$channels and subsequent opening of voltage-dependent $\mathrm{Ca}^{2+}$ channels on the plasma membranes of $\beta$-cells (12). This increased intracellular concentration of $\mathrm{Ca}^{2+}$ ultimately initiates insulin exocytosis in a process known as glucose-stimulated insulin secretion (GSIS) (12). Furthermore, completed cycles of the tricarboxylic acid (TCA) cycle generates one GTP molecule, which serves no direct influence on GSIS unless transformed to ATP $(13,14)$. However, GTP is an essential signal in insulin secretion in $\beta$-cells $(13,14)$. Numerous studies have investigated the association between mitochondrial dysfunction and $\beta$-cell failure, in addition to the pathogenesis of DM (7,15-18). Protecting mitochondrial function and the antioxidant ability of pancreatic $\beta$-cells may prove to be a beneficial future therapeutic target for type-2 DM, consistent with the previous reports $(9,19)$. The present review provides an overview of recent reports regarding the association between mitochondrial dysfunction and $\beta$-cell failure.

\section{Mitochondrial dysfunction}

Mitochondrial function. Mitochondria serve a number of roles in different cellular processes, with the most significant one of which is that of energetic powerhouses for cellular activities (20). 
Mitochondria produce ATP predominantly through OXPHOS, during which protons flow through ATP synthase located in the inner mitochondrial membrane (IMM) to drive ATP synthesis $(20,21)$. Specifically, electrons are transferred from $\mathrm{NADH}$ to oxygen through a chain of electron carriers collectively called the electron transport chain (ETC) (20). The four major protein complexes located in the IMM within the ETC are NADH-Q reductase (complex I), succinate-Q reductase (complex II), Q-cytochrome $c$ reductase (complex III) and cytochrome $c$ oxidase (complex IV). Complexes I, III and IV pump $\mathrm{H}^{+}$ions into the mitochondrial intermembranous space from the mitochondrial matrix to produce a gradient of $\mathrm{H}^{+}$ions when electrons are transported down the ETC (20). This generates a positive $\mathrm{H}^{+}$gradient on the side of the IMM that faces the intermembranous space. Subsequently, protons flow back into the mitochondrial matrix via ATP synthase, also called complex V, to produce ATP (20). Although the reduced form of flavin adenine dinucleotide $\left(\mathrm{FADH}_{2}\right)$ also produces ATP, the level of production is less than that of NADH, since $\mathrm{FADH}_{2}$ oxidation induces $\mathrm{H}^{+}$ions to be pumped out by complexes III and IV (20). Of note, mitochondria also serve as the main source of reactive oxygen species (ROS) in cells, which engage in ROS-mediated signaling and can activate pathways such as calcium signaling (22-24). Furthermore, mitochondria participate in intracellular metabolic processes, including the TCA cycle $(25)$, synthesis of heme $(26,27)$ and certain steroids, including adrenal hormone $(28,29)$, calcium storage in conjunction with the endoplasmic reticulum (ER) (30) and apoptotic regulation via cytochrome $c$ (31). Therefore, when mitochondria become dysfunctional, concurrent alterations in cellular phenotypes will occur.

Mitochondria-related genomic and proteomic abnormalities. Mitochondrial DNA (mtDNA) is a multi-copy, 16.6-kb circular double-stranded DNA molecule (32). The mitochondrial genome is most probably a remnant of an archaeon, $\alpha$-proteobacterium (33). However, most archaeon genes have been transmitted from the mitochondria into the nucleus and function as nuclear genes (33). The remaining mtDNA is comprised of 37 genes encoding 13 proteins, 22 transfer RNAs (tRNAs) and two ribosomal RNAs (rRNAs) (32). There are two main categories of mitochondrial genomic abnormalities: Maternally inherited genetic defects and acquired mutations. Due to the existence of mitochondrial genetic heteroplasmy, the precise association between mtDNA defects and disease remains unclear (34). For instance, based on the prevalence of mtDNA-related diseases in $2017, \geq 1$ in $10,000-15,000$ individuals in the general population is influenced by mtDNA-related cardiomyopathy worldwide, though the exact prevalence remains unknown (34). Accumulating evidence has demonstrated that in cases of mtDNA defects and mutations caused by pathogenic changes, including the overproduction of ROS, diseases emerge directly or indirectly due to these defects/mutations (15,16,34-36). In particular, DM, neuromuscular degenerative disease and perinatal lethality have all been previously associated with increased heteroplasmy levels of the mtDNA tRNA ${ }^{\text {Leu }}$ nucleotide mutation $(15,16,35,36)$.

Mitochondrial rRNAs are regulated by transcription factors (TFs) B1 (TFB1M) and B2 (TFB2M), both of which are essential mitochondrial TFs (37). Overexpression or $1555 \mathrm{~A}>\mathrm{G}$ mutation in TFB1M results in the over-production of methyltransferases, which in turn lead to the excessive methylation of mitochondrial rRNAs (17,37). In human mitochondria, the 5'-processing of several mitochondrial tRNAs is completed by the RNase P complex, consisting of mitochondrial RNase P Proteins (MRPP)1, MRRP2 and MRPP3 (38). MRPP1 and MRPP2 comprise a strong protein complex known as MRPP1/2 (39), where abnormal expression of MRPP1/2, caused by missense variants in tRNA methyltransferase 10 homolog $\mathrm{C}$, which encodes MRPP1, results in impaired mitochondrial RNA processing and defective mitochondrial protein synthesis $(39,40)$. In addition, other factors, such as phosphodiesterase 12 , have been previously demonstrated to regulate mitochondrial non-coding RNAs (41). Since mitochondrial mRNAs, tRNAs and non-coding RNAs are critical to mitochondrial biogenesis, abnormalities can lead to mitochondrial dysfunction $(17,18,37,39,41)$.

Proteins that participate in the ETC and OXPHOS, including complexes I-V, directly serve crucial roles in mitochondrial function and dysfunction $(20,42,43)$. Uncoupling proteins (UCPs) are closely associated with IMM potential $(44,45)$. Complexes I-IV in the ETC pump protons from the mitochondrial matrix into the IMM and the intermembranous space to establish a $\mathrm{H}^{+}$gradient, whilst UCPs (particularly UCP-1) in the IMM facilitate proton leakage to reduce the IMM potential, uncoupling the respiratory process from ADP phosphorylation $(42,46)$. During this process, UCPs render the final products derived from electron transport to be heat instead of ATP (Fig. 2) (42). This process is indispensable in brown adipose tissues for heat generation, particularly in newborn infants (47). However, in other cells, overexpression of UCPs results in the increased uncoupling of electron transport from ATP synthesis, thereby causing mitochondrial dysfunction $(48,49)$. The following sections discuss the association between these regulatory proteins and $\beta$-cell failure.

Mitochondrial impairment induced by ROS-induced metabolic stress. Mitochondria utilize large quantities of $\mathrm{O}_{2}$ for energy production. However, the ETC exhibits reduced efficiency due to proton leakage (50). When leakage occurs at the IMM between coenzyme $\mathrm{Q}$ and semi-ubiquinone, one electron instead of the usual two is passed onto one molecule of $\mathrm{O}_{2}$ to form superoxide anion radicals as the byproduct $(50,51)$. A free radical is an uncharged molecule that has an unpaired valence electron (52). Such $\mathrm{O}_{2}$ free radicals, including superoxide anions $\left(\mathrm{O}_{2}^{-}\right)$, are referred to as $\mathrm{ROS}$ and are strong oxidants (53).

When a large amount of ROS is produced, mitochondrial manganese superoxide dismutase (Mn-SOD) cannot scavenge oxidants at a sufficient rate (54). As a result, oxidative stress occurs and causes damage to mitochondrial components, such that degradative processes, including apoptosis, are initiated (51). Excessive ROS can create a vicious cycle in which ROS continues to induce mitochondrial damage via a positive-feedback mechanism that results in increased ROS production (55). Extensive investigation has previously revealed the mechanism by which ROS causes damage to DNA, proteins, cellular lipids and organs, including the kidneys and blood vessels (56-58). Increased levels of $\mathrm{O}_{2}{ }^{--}$in 


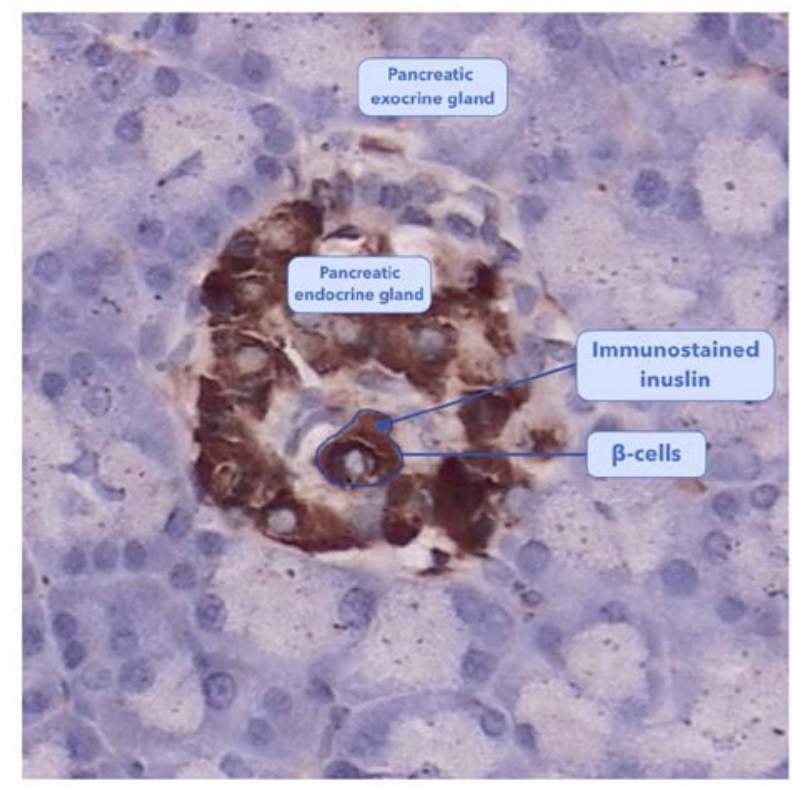

Figure 1. Endocrine and exocrine glands of the pancreas. The pancreas consists of endocrine glands that are surrounded by exocrine glands. The majority of the endocrine glands are comprised of $\beta$-cells. Insulin is contained within $\beta$-cells, as presented by immunostaining of the avidin-biotin peroxidase complex. Magnification, $\mathrm{x} 40$.

afferent arterioles have been found to decrease nitric oxide NO production, resulting in afferent arteriole vasoconstriction and low glomerular filtration rate (58).

During hyperglycemia, which is caused by a high-sugar diet or genetic mutations, the concentration of intracellular glucose is elevated and glycolysis substrates become more available in $\beta$-cells, which then accelerates glycolysis, TCA cycle and pyruvate oxidation $(59,60)$. This metabolic stress causes an increased flux via OXPHOS, increasing the mitochondrial membrane potential beyond a critical threshold, resulting in blockage of the ETC at complex III $(61,62)$. Electrons trapped in complex III may leak, reducing $\mathrm{O}_{2}$ to form $\operatorname{ROS}(61,62)$. Although the number of mitochondria can increase to partially compensate for this metabolic stress, their functionalities or efficiencies do not seem to correspondingly increase, which was previously demonstrated by a mouse model (63-65). By contrast, increased mitochondrial density has actually been observed to increase ROS production (66).

The IMM is rich in cardiolipin, a phospholipid which has a high affinity for ROS and is particularly susceptible to ROS attack (67). When a cardiolipin is oxidized by ROS, excessive cytochrome $c$ attached to the cardiolipin is released into the cytosol, inducing apoptosis (67). Additionally, the products of phospholipid peroxidation may undergo fragmentation to form reactive intermediates, including malondialdehyde and 4-hydroxy-trans-2-nonenal (68). These substances can interfere with the ETC and inactivate ETC components by forming adducts, causing mitochondrial dysfunction $(67,68)$. Consequently, the mitochondria-dependent pathway of apoptosis may be activated by the release of mitochondrial content (e.g., cytochrome $c$ ) through the IMM (69). Therefore, whilst ROS held at tightly regulated levels serves as a signaling molecule that regulates cellular metabolism and apoptosis, excessive ROS can mediate destructive processes $(22,55)$.
Specific phenomena emerging following mitochondrial dysfunction. The consequences of mitochondrial dysfunction can vary according to specific conditions. Under the same pathogenic conditions, mitochondria with functional deficiencies exhibit diverse behaviors (16). Most commonly, dysfunctional mitochondria with morphological abnormalities such as hypertrophy frequently exhibit a rounded instead of an elliptical shape (66). Numerous studies have reported an increase in mitochondrial density during hyperglycemia $(7,66,70)$. However, earlier studies have reported a reduction in mitochondrial density during hyperglycemia $(71,72)$. Hence, this phenomenon appears to depend on the specific experimental models, subjects, tissues, cell types and examined pathological states. The microstructures of proteins within mitochondria can also change following mitochondrial dysfunction $(73,74)$. Complexes I and III in the ETC produce large amounts of ROS and, therefore, are particularly vulnerable to ROS damage among all mitochondrial proteins $(73,74)$. Complexes I and III have been observed to alter their conformation following $\operatorname{ROS}$ damage $(73,74)$. Furthermore, mitophagy and the mitochondrial-dependent pathway of apoptosis may eventually occur due to mitochondrial dysfunction (67,75). Mitophagy is a specialized form of autophagy that regulates damaged and dysfunctional mitochondria, where damaged mitochondria are scavenged or all mitochondria are eliminated during specific developmental stages, including fertilization, blood-cell maturation and starvation (75). During mitophagy, autophagosomes are usually formed through the phosphatase and tensin homolog-induced kinase 1/Parkin pathway (75). Following this, the autophagic lysosomal degradative pathway is activated (76). Exosomes may have a close association with mitophagy $(10,77)$. Recent studies have demonstrated that exosomes can carry intracellular components, including proteins, mRNAs, microRNAs and lipids, across the extracellular environment $(10,78)$. In total, $\leq 10 \%$ exosomal proteins are derived from mitochondria (77). Exosomes containing mitochondrial proteins can either be transferred from an unhealthy cell with mitochondrial dysfunction to a healthy cell to interfere with metabolism, or from a healthy cell to an unhealthy cell with mitochondrial dysfunction to facilitate metabolism (10). Therefore, exosomes may enable cells to remove peroxidated cardiolipins to maintain a healthy mitochondrial population (10). However, the definitive mechanism and consequence of exosomal transfer of mitochondrial proteins remains poorly understood and requires further study.

When the IMM is damaged by oxidative stress, certain proapoptotic proteins are exported into the cytosol (69). These proapoptotic proteins hinder ATP synthesis by disturbing the mitochondrial transmembrane potential, oxidizing $\mathrm{NADH}$, NADPH and glutathione (GSH) (69). This deteriorates mitochondrial metabolism and induces a vicious cycle of ROS damage (69). These proapoptotic proteins, including cytochrome $c$, ultimately initiate a cascade of caspase-dependent apoptosis (67). Cytochrome $c$ becomes unchained to cardiolipin in the IMM when a cardiolipin is oxidized by ROS (69). This release of cytochrome $c$ is then transported from the intermembranous space into the cytosol through membranous pores in the outer mitochondrial membrane (OMM). In response to cytochrome $c$ release, apoptotic protease 


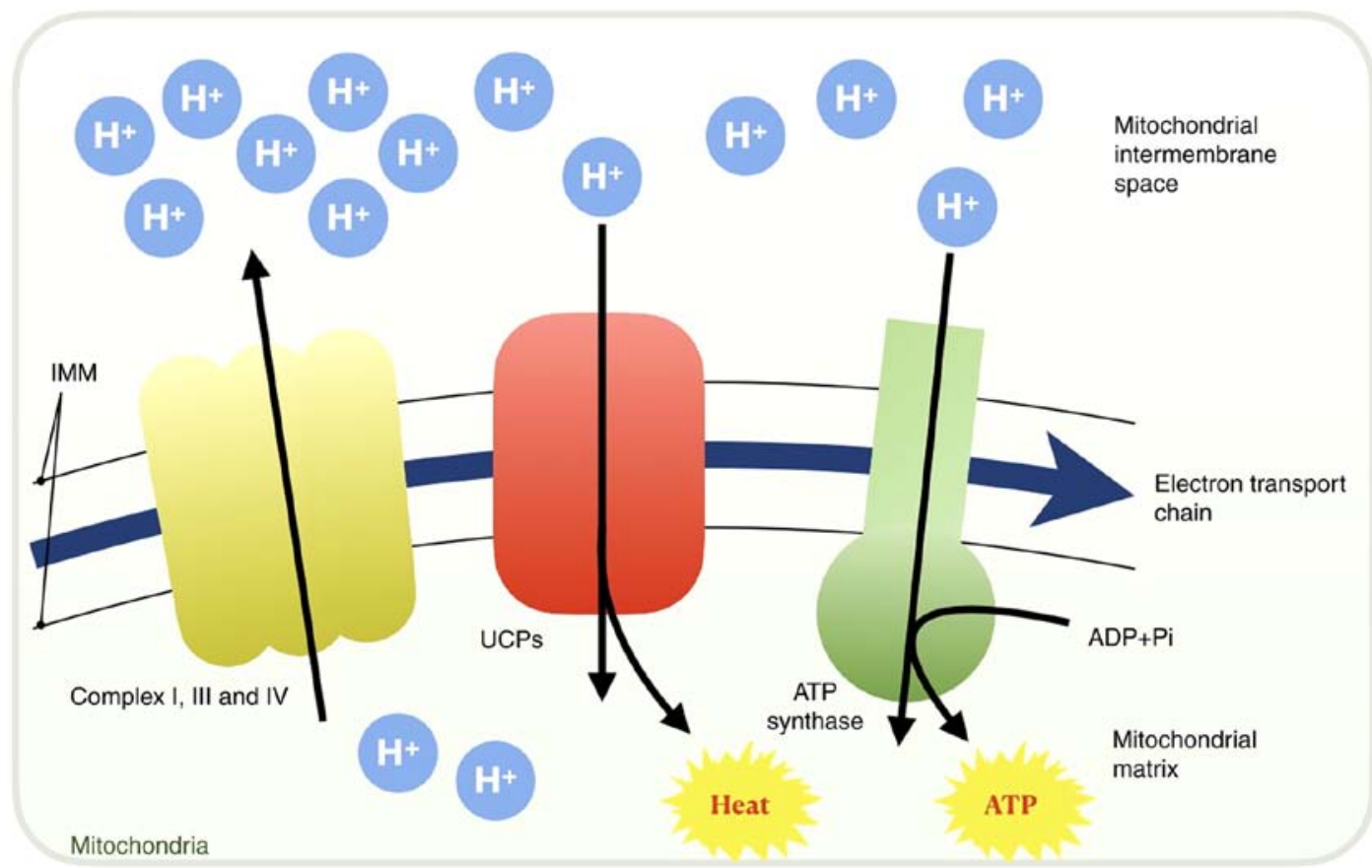

Figure 2. ETC in mitochondria. As electrons are transported through the ETC, $\mathrm{H}^{+}$in the mitochondrial matrix are pumped out into the intermembrane space to form an $\mathrm{H}^{+}$gradient. In a complete ETC, protons in the intermembranous space flow back into the mitochondrial matrix and drive ATP synthase to generate ATPs. UCPs in the IMM allow $\mathrm{H}^{+}$to flow back into the mitochondrial matrix to generate heat. ETC, electron transport chain; $\mathrm{H}^{+}$, protons; ATP, adenosine triphosphate; UCPs, uncoupling proteins; IMM, inner mitochondrial membrane; ADP, adenosine diphosphate; Pi, inorganic phosphate.

activating factor-1 (Apaf-1) oligomerizes (79). Following this, cytochrome $c$, Apaf-1 and procaspase-9 form the multiprotein apoptosome, which activates caspase- 9 and initiates the mitochondria-dependent pathway of apoptosis (69).

\section{Association between mitochondrial dysfunction and islet $\beta$-cell failure}

The mechanism of GSIS. Insulin secretion is regulated by numerous metabolic processes, including glycolysis and dehydrogenation, and depends on the level of blood sugar (13). GSIS is the principle mechanism by which insulin is secreted and it involves several processes, including the glycolysis of glucose, the transformation of pyruvate, the production of ATP and finally the opening of voltage-dependent $\mathrm{Ca}^{2+}$ channels (80-82). $\beta$-cells intake glucose into the cytosol via glucose transporter 2 on the plasma membrane (80). Cytosolic glucose undergoes glycolysis to produce pyruvate following phosphorylation by glucokinase (13). This pyruvate is then dehydrogenized into acetyl-coenzyme A by the pyruvate dehydrogenase complex and is transported into the mitochondria, where it generates ATP through the TCA cycle and OXPHOS to increase cytosolic ATP concentration (13). This results in the closure of ATP-sensitive $\mathrm{K}^{+}$channels and the opening of voltage-dependent $\mathrm{Ca}^{2+}$ channels on the plasma membrane to allow $\mathrm{Ca}^{2+}$ entry into the cytosol, which induces insulin exocytosis (13). Therefore, mitochondrial OXPHOS in islet $\beta$-cells is crucial during GSIS $(81,82)$.

Abnormalities in mitochondrial genes and proteins leading to $\beta$-cell dysfunction. It is beyond the scope of the present review to discuss all of the mitochondrial genes and proteins.
Previous reviews have comprehensively described how these genes and proteins are associated with DM. In subsequent sections, various examples of abnormalities in mitochondrial genes and proteins leading to $\beta$-cell dysfunction, including TFs, are discussed $(16,83,84)$.

Previous studies have demonstrated that the m.3243A $>\mathrm{G}$ mutation in the mitochondrial gene RNA $^{\text {Leu }}$ causes maternally inherited diabetes and deafness (MIDD) syndrome $(85,86)$. This mutation can interfere with the expression or function of other mitochondrial genes (for instance, m.16093T $>C$ ) to induce mitochondrial dysfunction (85). Dysfunctional mitochondria produce less ATP, which further impairs insulin secretion, since the $\mathrm{K}^{+}$channels required for insulin release from $\beta$-cells are ATP-sensitive (13). A previous study demonstrated that human patients with this mutation develop increased gluconeogenesis which, alongside insulin resistance, results in increased ROS production by dysfunctional mitochondria in tissues such as skeletal muscle to induce DM (87).

Nicotinamide nucleotide transhydrogenase (NNT) catalyzes the reversible conversion of $\mathrm{NADP}^{+}$and $\mathrm{NADH}$ into NADPH and $\mathrm{NAD}^{+}$, respectively, in mitochondria (88). Primitive studies in mice have previously suggested that a lack of NNT is associated with impaired insulin secretion (88). Another previous study revealed that a lack of NNT hinders GSIS by altering $\mathrm{Ca}^{2+}$-induced exocytosis and its metabolic amplification instead of altering glucose-mediated stimulation of $\mathrm{Ca}^{2+}$ influx or other mitochondrial events further upstream (89). In summary, dysfunctional mitochondria lacking NNTs lead to the failure of $\mathrm{Ca}^{2+}$-induced exocytosis of insulin from $\beta$-cells.

Cytochrome $c$ serves a pivotal role in the mitochondria-dependent pathway of apoptosis in $\beta$-cells (69). It is 
widely acknowledged that a high rate of $\beta$-cell apoptosis due to increased cytoplasmic levels of cytochrome $c$ occurs prior to DM (90). Upregulated expression of cytochrome $c$ and apoptosis have been previously observed in muscle biopsies from patients with DM (91). Cyclin dependent kinase 11A (CDC2L2) is a gene that is a risk factor for type-2 DM $(92,93)$. High expression of p58, which is encoded by CDC2L2 in $\beta$-cells, increases OMM permeability to enable cytochrome $c$ leakage into the cytosol to exacerbate ER stress, ultimately leading to apoptosis $(92,93)$. However, the mechanism of how upregulated cytochrome $c$ induces $\beta$-cell failure in the cytosol remains unclear.

The potential role of UCPs in the modulation of insulin secretion in response to glucose has been the focus of research attention. UCP-2 is a negative regulator during pancreatic development (46) and silences glucose oxidation in $\beta$-cells, which is the initial process of GSIS (94). Previous studies have demonstrated that upregulated UCP-2 and downregulated UCP-3 under chronic high glucose conditions impaired GSIS in $\beta$-cells $(43,95)$. However, how UCP-2 is involved in DM remains unclear. However, using the same experimental model of streptozotocin-induced diabetic mice, a previous study demonstrated that the destruction of $\beta$-cells during autoimmune DM is more severe in UCP-2 $2^{--}$mice (96), while another study has hypothesized that enhanced $\beta$-cell function is associated with higher basal ROS levels constitutively activating the ROS-signaling pathway in UCP- $2^{--}$mice, resulting in significantly reduced severity of hyperglycemia (97). Collectively, these findings indicated that the mitochondrial protein UCP-2 is has multiple roles $\beta$-cell failure.

TFs A, B1M and B2M mediate the transcription of mtDNA, where TFB1M mainly serves as a dimethyl transferase (37). Reduced TFB1M expression, damaged islets and dysfunctional mitochondria have all been previously observed in heterozygous $\mathrm{TFB}_{1 \mathrm{M}}^{+/-}$mice (98). As a result, $\beta$-cells in islets release less insulin in response to glucose, since less ATP is produced by these dysfunctional mitochondria $(16,83,98)$. Additionally, previous studies have demonstrated that GSIS is impaired and $\beta$-cell mass is reduced during mitochondrial dysfunction due to a lack of TFB2M in mitochondria $(17,99)$.

To preserve cell viability, impaired mitochondria can be removed by exosomes that carry mitochondrial fragments out of the cells (100). If exosomes transporting unwanted or harmful fragments from unhealthy $\beta$-cells are received by healthy $\beta$-cells nearby, the metabolism of recipient healthy $\beta$-cells may become disturbed. Dysfunctional mitochondria within one $\beta$-cell can induce $\beta$-cell failure in adjacent cells (10). However, further research is required to investigate these possibilities further (10).

ROS: The initial destroyer of islet $\beta$-cells. Continuous deposition of glucose into the plasma from a constant high-carbohydrate diet results in a high basal level of plasma glucose (101). Additionally, since the rate of glucose transportation across the $\beta$-cell membrane is higher compared with the rate of glucose phosphorylation, glucose then accumulates within the cytosol of $\beta$-cells (102). Increased glucose influx into $\beta$-cells increases the activity of the TCA cycle, generating more ATP by OXPHOS to raise the level of $\mathrm{Ca}^{2+}$ in the $\beta$-cell cytosol to stimulate insulin secretion via GSIS (13). Mitochondrial oxidative activity then reaches its maximum capacity and may produce more ROS $(60,103,104)$. Furthermore, at the end of the GSIS signaling pathway, elevated intracellular $\mathrm{Ca}^{2+}$ serves as a signal to stimulate mitochondrial ROS generation (105) and activate protein kinase $\mathrm{C}$, which initiates the NADPH oxidase-dependent generation of superoxides and other free radicals $(60,106)$. Previous studies have demonstrated that ROS production increases with the degree of obesity and hyperglycemia $(107,108)$.

Mitochondria are the major source of ROS in islet $\beta$ cells (109). Following dismutation by $\mathrm{Mn}-\mathrm{SOD}, \mathrm{O}_{2}{ }^{--}$is converted into the less reactive $\mathrm{H}_{2} \mathrm{O}_{2}$, which can diffuse through aquaporins located in mitochondrial membranes (22). If $\mathrm{H}_{2} \mathrm{O}_{2}$ cannot be removed in a timely manner, excessive $\mathrm{H}_{2} \mathrm{O}_{2}$ will be converted into the highly reactive hydroxyl radical HO (109). The capacity of scavenging oxidants in $\beta$-cells is different from that in other cells. An earlier study has indicated that $\beta$-cells express lower levels of antioxidant enzymes, including Mn-SODs, glutathione peroxidases (GPXs) and catalases (110). As a compensatory mechanism, $\beta$-cells are rich in other peroxidase-based antioxidant enzymes, including glutaredoxin and thioredoxin $(110,111)$. However, once the levels of oxidative species exceed the levels of antioxidants, abnormal accumulation of ROS results in pro-oxidative conditions (104). $\mathrm{O}_{2}{ }^{--}$can oxidize NO to produce peroxinitrite $\left(\mathrm{ONOO}^{-}\right)$and initiate an oxidation cascade, which severely oxidizes proteins, lipids and carbohydrates (112). Additionally, other types of ROS can damage cellular components through nitration, carbonylation, peroxidation and nitrosylation modifications (113). Ultimately, defective gene expression, reduced glucose secretion and increased $\beta$-cell apoptosis occur due to prolonged exposure to ROS (54).

Excessive ROS such as $\mathrm{O}_{2}^{-}$and $\mathrm{H}_{2} \mathrm{O}_{2}$, can alter the structure and function of proteins and lipids, particularly in the mitochondria, leading to a chain reaction of impaired mitochondrial function, reduced ATP production and defective insulin secretion (103). Additionally, these oxidants break single-strand DNAs and initiate apoptosis through caspase activation (69). A key mediator of apoptosis may be $\mathrm{ONOO}^{-}$, which can concomitantly trigger nitrosative stress (114). Therefore, mitochondria are the source and target of these reactive species $(69,103,109,114)$. Oxidative damage contributes to the difficulty of scavenging ROS (115-118). Under conditions of excessive ROS, protective antioxidant mechanisms deteriorate due to the oxidative destruction of antioxidant enzymes, which exaggerates the imbalance between oxidants and antioxidants (116-118). When the intracellular concentration of glucose is high, glucose can be transformed into sorbitol through the polyol pathway (115). Sorbitol consumes antioxidants, including NADPH and GSH, resulting in increased ROS production (115). This type of ROS accumulation then inhibits glucose-6-phosphate dehydrogenase (G6PDH), which is crucial for reducing intracellular glucose levels (115). Additionally, since the production of NADPH involves the pentose phosphate pathway, where G6PDH catalyzes glucose-6-phosphate to generate ribose 5-phosphate and NADPH, the inhibition of G6PDH reduces NADPH levels to consequently decrease those of GSH, further aggravating oxidative stress (116-118). 


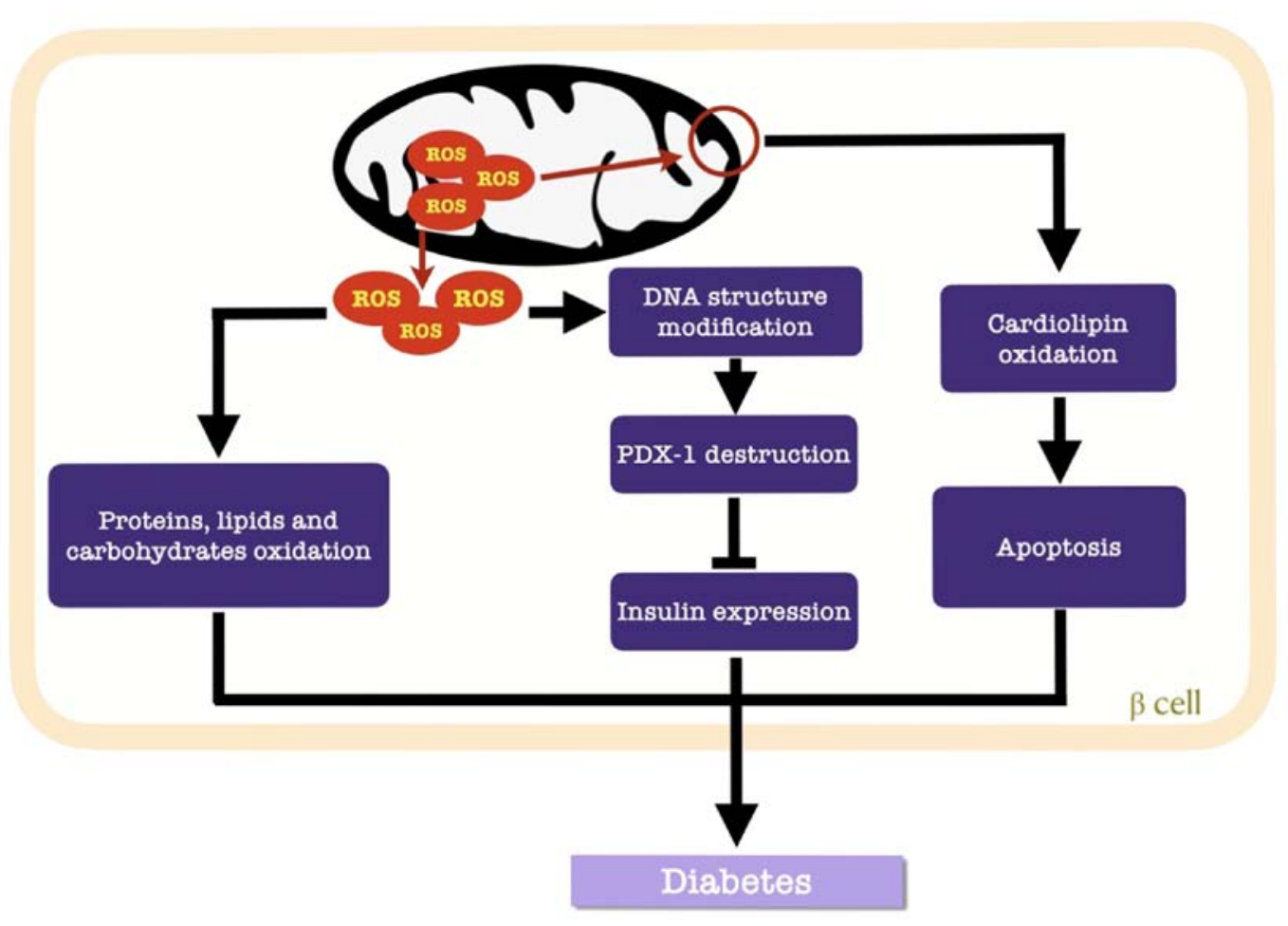

Figure 3. Effects of ROS accumulation on mitochondrial function. Mitochondrial impairment and structural destruction lead to the accumulation of ROS. This accumulation within mitochondria induces apoptosis via the oxidation of cardiolipin. Excess ROS are released into the cytosol of $\beta$-cells and oxidize proteins, lipids and carbohydrates. Additionally, ROS can modify the DNA structure to inhibit insulin expression by suppressing PDX-1 activity. These processes results in diabetes. ROS, reactive oxygen species; PDX-1, pancreatic duodenal homeobox 1.

UCPs maintain glucose homeostasis by regulating insulin secretion (119). Although UCP-1 has been reported to downregulate ROS generation, its mechanism of action remains unclear $(120,121)$. Increased ROS, in particular $\mathrm{O}_{2}{ }^{-}$, activates UCP-2 by generating carbon radicals, which peroxidize unsaturated side chains of fatty acid substituents in mitochondrial phospholipids such as cardiolipin (67). Subsequently, UCP-2 overexpression results in $\beta$-cell failure due to damaged GSIS (122). Nonetheless, the mechanism underlying the activation of UCP-2 by ROS and the precise effects of UCP-2 on insulin secretion remain unclear (123). Numerous studies on UCP-3 have focused on insulin resistance or insulin sensitivity instead of $\beta$-cell insulin secretion $(124,125)$. A previous study has indicated that the progressive reduction in UCP-3 levels results in insulin resistance (124), though the function of UCP-3 remain unclear (126).

Cardiolipin is a constructive phospholipid in the IMM that is vulnerable to ROS (67). Once the IMM is perforated, cytochrome $c$-mediated apoptosis is initiated (69). Additionally, the destructive nature of ROS involves structural modifications in DNA (127) and alterations in gene expression (54). Pancreatic duodenal homeobox 1 (PDX-1) is a target of ROS in $\beta$ cells, where $\mathrm{H}_{2} \mathrm{O}_{2}$ suppresses the DNA binding activity of PDX-1 to consequently downregulate insulin gene expression (Fig. 3) (60).

Based on these aforementioned observations, DM therapies aimed at reducing ROS levels or increasing the antioxidant defenses of $\beta$-cells have become a focus of interest $(9,128,129)$. GPX4 is a GPX selenoprotein that has been reported to repair oxidized mitochondrial membranes $(128,130)$. The phospholipase $\mathrm{A}_{2}$ family catalyzes the hydrolysis of $\mathrm{SN}-2$ fatty acyl bond of phospholipids, which repair oxidized membranous phospholipids (9). Defective GSIS can be ameliorated by fatty-acid-oxidation inhibitors or glucose-oxidation promoters $(9,128-131)$. Gene therapy that upregulate the expression levels of glutaredoxin and thioredoxin can potentially improve the capacity of scavenging the excess ROS in $\beta$-cells (131). Furthermore, dietary interventions and exercise help mitigate the progression of DM (129). Reduced intake and increased output of glucose can also alleviate the pressure of oxidative stress within $\beta$-cell mitochondria, whilst exercise strengthens mitochondrial function and increase peripheral insulin sensitivity (129).

Inflammatory attack against islet $\beta$-cells. Unhealthy, dying or damaged $\beta$-cells transmit immunogenic signals to activate immune cells in pancreatic islets (132). Reduced UCP-2 gene expression in mononuclear cells of individuals who are obese and diabetic may contribute to metabolic disorders due to immunological abnormalities (133). These activated immune cells release inflammatory cytokines and chemokines, which activate macrophages and $\mathrm{T}$ cells within and around pancreatic islets, amplifying inflammation (134). Cytokines such as IL-1 $\beta$ have been documented to inhibit insulin secretion (134). These metabolic perturbations increase the number of dysfunctional or apoptotic $\beta$-cells (134). Cytokine-induced $\beta$-cell dysfunction or apoptosis is associated with complex gene networks that are controlled by transcription factors, including NF- $\kappa \mathrm{B}$ and those that belong to the STAT family (135). NF- $\kappa \mathrm{B}$ is derived from ER stress signals, whilst members of the STAT family serve as signal transducers and activators (135). Parkin is a RING-between-RING-type E3 ubiquitin ligase that 
modulates the K63 ubiquitination status of receptor-interacting serine/threonine-protein kinase 1 to promote $\mathrm{NF}-\kappa \mathrm{B}$ activation (136). These inflammation-stimulating reactions result in the activation of $\mathrm{NF}-\kappa \mathrm{B}$, which then triggers the transcription of genes associated with pro-inflammatory responses (66). Myeloid differentiation primary response gene 88 (MyD88) and interleukin-1 receptor-associated kinase (IRAK) are regulated by $\mathrm{NF}-\kappa \mathrm{B}$ (137). MyD88 and IRAK serve indispensable roles in the pathogenesis of type-1 DM (138). NF- $\kappa \mathrm{B}$ activation enhances the transcription of proapoptotic proteins whilst inhibiting that of antiapoptotic proteins in $\beta$-cells, leading to higher permeability of mitochondrial membranes $(103,139)$. Additionally, cytochrome $c$ may be released through the highly permeable mitochondrial membranes, resulting in apoptosis (71). High quantities of $\mathrm{Ca}^{2+}$ released into $\beta$-cell cytosol from the damaged ER during inflammation can also contribute to $\beta$-cell apoptosis $(60,105,140)$. Angiotensin II, which induces IL-1-mediated inflammation, has been previously found to enhance $\beta$-cell apoptosis, weaken mitochondrial function and insulin secretion (141).

Clinical trials, in vivo and in vitro studies, have provided useful evidence indicating that monotherapy or adjuvant therapy targeting IL-1 $\beta$ in type-2 DM can confer long-term benefits against blood sugar and mitigating diabetic complications $(134,142)$. Furthermore, sulforaphane is currently being developed as a nutraceutical to preserve $\beta$-cell function due to its reported antioxidative and anti-inflammatory properties, along with its abilities to preserve and improve mitochondrial bioenergetic function (143). Therefore, inflammation modulation may prove to be a useful future therapeutic target for type-2 DM $(144,145)$.

\section{Conclusion}

Mitochondrial dysfunction in $\beta$-cells serves a central role in the pathogenesis of DM. Specifically, timely insulin secretion in response to increased serum glucose depends on whether OXPHOS in mitochondria functions sufficiently to increase ATP concentrations in islet $\beta$-cells, leading to increased cytosolic $\mathrm{Ca}^{2+}$ and insulin exocytosis. Accumulating data have indicated that genetic defects such as those in MIDD, mutations such as those in TFB1 and TFB2M, dysregulated gene expression such as that of UCPs in mitochondria, excessive ROS, cytokine impairment and unwanted exosomes received from other mitochondria, can all lead to mitochondrial dysfunction. Nevertheless, the mechanism of these pathogenic processes remain unclear. Further research into the association between dysfunctional mitochondria and $\beta$-cell failure may lead to breakthroughs in the treatment of DM. Use of insulin injections to downregulate blood sugar cannot fully prevent or treat diabetic complications, since this therapy does not target DM pathogenesis. In summary, previous research has indicated that protection of mitochondrial function, enhancement of antioxidants and regulation of transcription factors in islet $\beta$-cells may be potential therapeutic targets for DM.

\section{Acknowledgements}

Not applicable.

\section{Funding}

The current review was supported by the Ningbo Science and Technology Innovation Team Program (grant no. 2014B82002), the Ningbo 3315 Program (grant no. 2013A-10-G) and the National Natural Science Foundation of China (grant no. 81370165$)$.

\section{Availability of data and materials}

Not applicable.

\section{Authors' contributions}

SB designed the present study. WS prepared and wrote the manuscript. FH performed literature research and selected the included studies. All authors read and approved the final manuscript.

\section{Ethics approval and consent to participate}

Not applicable.

\section{Patient consent for publication}

Not applicable.

\section{Competing interests}

The authors declare that they have no competing interests.

\section{References}

1. Schmidt AM: Highlighting diabetes mellitus: The epidemic continues. Arterioscler Thromb Vasc Biol 38: e1-e8, 2018.

2. Wang YJ, Schug J, Won KJ, Liu C, Naji A, Avrahami D, Golson ML and Kaestner KH: Single-cell transcriptomics of the human endocrine pancreas. Diabetes 65: 3028-3038, 2016.

3. Lawlor N, George J, Bolisetty M, Kursawe R, Sun L, Sivakamasundari V, Kycia I, Robson P and Stitzel ML: Single-cell transcriptomes identify human islet cell signatures and reveal cell-type-specific expression changes in type 2 diabetes. Genome Res 27: 208-222, 2017.

4. Huang Q, Bu S, Yu Y, Guo Z, Ghatnekar G, Bu M, Yang L, Lu B, Feng Z, Liu S and Wang F: Diazoxide prevents diabetes through inhibiting pancreatic beta-cells from apoptosis via Bcl-2/Bax rate and $\mathrm{p} 38$-beta mitogen-activated protein kinase. Endocrinology 148: 81-91, 2007.

5. International Diabetes Federation. IDF Diabetes Atlas, 8th edition. International Diabetes Federation, Brussels 2017. Available from: $\mathrm{http} / / / \mathrm{www}$.diabetesatlas.org.

6. Holman N, Young B and Gadsby R: Current prevalence of type 1 and type 2 diabetes in adults and children in the UK. Diabet Med 32: 1119-1120, 2015.

7. Blake R and Trounce IA: Mitochondrial dysfunction and complications associated with diabetes. Biochim Biophys Acta 1840: 1404-1412, 2014

8. Ma RCW: Epidemiology of diabetes and diabetic complications in China. Diabetologia 61: 1249-1260, 2018.

9. Ma ZA, Zhao Z and Turk J: Mitochondrial dysfunction and $\beta$-cell failure in type 2 diabetes mellitus. Exp Diabetes Res 2012: 703538, 2012

10. Montgomery MK: Mitochondrial dysfunction and diabetes: Is mitochondrial transfer a friend or foe? Biology (Basel) 8: 33, 2019.

11. van der Bliek AM, Sedensky MM and Morgan PG: Cell biology of the mitochondrion. Genetics 207: 843-871, 2017.

12. Henquin JC: Triggering and amplifying pathways of regulation of insulin secretion by glucose. Diabetes 49: 1751-1760, 2000 . 
13. Komatsu M, Takei M, Ishii H and Sato Y: Glucose-stimulated insulin secretion: A newer perspective. J Diabetes Investig 4: 511-516, 2013.

14. Kibbey RG, Pongratz RL, Romanelli AJ, Wollheim CB, Cline GW and Shulman GI: Mitochondrial GTP regulates glucose-stimulated insulin secretion. Cell Metab 5: 253-264, 2007.

15. Molnar MJ and Kovacs GG: Mitochondrial diseases. Handb Clin Neurol 145: 147-155, 2017.

16. Fex M, Nicholas LM, Vishnu N, Medina A, Sharoyko VV, Nicholls DG, Spégel P and Mulder H: The pathogenetic role of $\beta$-cell mitochondria in type 2 diabetes. J Endocrinol 236 R145-R159, 2018.

17. O'Sullivan M, Rutland P, Lucas D, Ashton E, Hendricks S, Rahman S and Bitner-Glindzicz M: Mitochondrial m.1584A 12S m62A rRNA methylation in families with $\mathrm{m} .1555 \mathrm{~A}>\mathrm{G}$ associated hearing loss. Hum Mol Genet 24: 1036-1044, 2015.

18. Bohnsack MT and Sloan KE: The mitochondrial epitranscriptome: The roles of RNA modifications in mitochondrial translation and human disease. Cell Mol Life Sci 75: 241-260, 2018.

19. SubramanianS,KalyanaramanB and Migrino RQ: Mitochondrially targeted antioxidants for the treatment of cardiovascular diseases Recent Pat Cardiovasc Drug Discov 5: 54-65, 2010.

20. Papa S, Martino PL, Capitanio G, Gaballo A, De Rasmo D Signorile A and Petruzzella V: The oxidative phosphorylation system in mammalian mitochondria. Adv Exp Med Biol 942: 3-37, 2012

21. Conley KE: Mitochondria to motion: Optimizing oxidative phosphorylation to improve exercise performance. J Exp Biol 219: 243-249, 2016

22. Waypa GB, Smith KA and Schumacker PT: O2 sensing, mitochondria and ROS signaling: The fog is lifting. Mol Aspects Med 47-48: 76-89, 2016.

23. Angelova PR and Abramov AY: Functional role of mitochondrial reactive oxygen species in physiology. Free Radic Biol Med 100: $81-85,2016$.

24. Kausar S, Wang F and Cui $\mathrm{H}$ : The role of mitochondria in reactive oxygen species generation and its implications for neurodegenerative diseases. Cells 7: 274, 2018.

25. Akram M: Citric acid cycle and role of its intermediates in metabolism. Cell Biochem Biophys 68: 475-478, 2014

26. Chiabrando D, Mercurio S and Tolosano E: Heme and erythropoieis: More than a structural role. Haematologica 99: 973-983, 2014.

27. Moreno-Navarrete JM, Rodríguez A, Ortega F, Becerril S Girones J, Sabater-Masdeu M, Latorre J, Ricart W, Frühbeck G and Fernández-Real JM: Heme biosynthetic pathway is functionally linked to adipogenesis via mitochondrial respiratory activity. Obesity (Silver Spring) 25: 1723-1733, 2017.

28. Elustondo P, Martin LA and Karten B: Mitochondrial cholesterol import. Biochim Biophys Acta Mol Cell Biol Lipids 1862 : 90-101, 2017.

29. Martin LA, Kennedy BE and Karten B: Mitochondrial cholesterol: Mechanisms of import and effects on mitochondrial function. J Bioenerg Biomembr 48: 137-151, 2016.

30. Bravo-Sagua R, Parra V, López-Crisosto C, Díaz P, Quest AF and Lavandero S: Calcium transport and signaling in mitochondria. Compr Physiol 7: 623-634, 2017.

31. Wang C, Du J, Du S, Liu Y, Li D, Zhu X and Ni X: Endogenous $\mathrm{H} 2 \mathrm{~S}$ resists mitochondria-mediated apoptosis in the adrenal glands via ATP5A1 S-sulfhydration in male mice. Mol Cell Endocrinol 474: 65-73, 2018.

32. Yan C, Duanmu X, Zeng L, Liu B and Song Z: Mitochondrial DNA: Distribution, mutations, and elimination. Cells 8: 379, 2019

33. Roger AJ, Muñoz-Gómez SA and Kamikawa R: The origin and diversification of mitochondria. Curr Biol 27: R1177-R1192, 2017.

34. Stefano GB, Bjenning C, Wang F, Wang N and Kream RM: Mitochondrial heteroplasmy. Adv Exp Med Biol 982: 577-594, 2017.

35. Saneto RP: Genetics of mitochondrial disease. Adv Genet 98: 63-116, 2017

36. Kopinski PK, Janssen KA, Schaefer PM, Trefely S, Perry CE, Potluri P, Tintos-Hernandez JA, Singh LN, Karch KR, Campbell SL, et al: Regulation of nuclear epigenome by mitochondrial DNA heteroplasmy. Proc Natl Acad Sci USA 116: 16028-16035, 2019.

37. Cotney J, McKay SE and Shadel GS: Elucidation of separate, but collaborative functions of the rRNA methyltransferase-related human mitochondrial transcription factors B1 and B2 in mitochondrial biogenesis reveals new insight into maternally inherited deafness. Hum Mol Genet 18: 2670-2682, 2009.
38. Karasik A, Fierke CA and Koutmos M: Interplay between substrate recognition, 5 'end tRNA processing and methylation activity of human mitochondrial RNase P. RNA 25: 1646-1660, 2019.

39. Reinhard L, Sridhara S and Hallberg BM: The MRPP1/MRPP2 complex is a tRNA-maturation platform in human mitochondria. Nucleic Acids Res 45: 12469-12480, 2017.

40. Metodiev MD, Thompson K, Alston CL, Morris AAM, He L, Assouline Z, Rio M, Bahi-Buisson N, Pyle A, Griffin H, et al: Recessive mutations in TRMT10C cause defects in mitochondrial RNA processing and multiple respiratory chain deficiencies. Am J Hum Genet 98: 993-1000, 2016.

41. Pearce SF, Rorbach J, Van Haute L, D'Souza AR, RebeloGuiomar P, Powell CA, Brierley I, Firth AE and Minczuk M: Maturation of selected human mitochondrial tRNAs requires deadenylation. Elife 6: e27596, 2017.

42. Ricquier D: UCP1, the mitochondrial uncoupling protein of brown adipocyte: A personal contribution and a historical perspective. Biochimie 134: 3-8, 2017.

43. Li Y, Maedler K, Shu L and Haataja L: UCP-2 and UCP-3 proteins are differentially regulated in pancreatic beta-cells. PLoS One 3: e1397, 2008.

44. Pitt MA: Overexpression of uncoupling protein-2 in cancer: Metabolic and heat changes, inhibition and effects on drug resistance. Inflammopharmacology 23: 365-369, 2015.

45. Chan SHH and Chan JYH: Mitochondria and reactive oxygen species contribute to neurogenic hypertension. Physiology (Bethesda) 32: 308-321, 2017.

46. Broche B, Ben Fradj S, Aguilar E, Sancerni T, Bénard M, Makaci F, Berthault C, Scharfmann R, Alves-Guerra MC and Duvillié B: Mitochondrial protein UCP2 controls pancreas development. Diabetes 67: 78-84, 2018.

47. Oelkrug R, Polymeropoulos ET and Jastroch M: Brown adipose tissue: Physiological function and evolutionary significance. J Comp Physiol B 185: 587-606, 2015.

48. Giralt $M$ and Villarroya F: Mitochondrial uncoupling and the regulation of glucose homeostasis. Curr Diabetes Rev 13: 386-394, 2017.

49. $\mathrm{Hu} \mathrm{M}$, Lin $\mathrm{H}$, Yang $\mathrm{L}$, Cheng $\mathrm{Y}$ and Zhang $\mathrm{H}$ : Interleukin-22 restored mitochondrial damage and impaired glucose-stimulated insulin secretion through down-regulation of uncoupling protein-2 in INS-1 cells. J Biochem 161: 433-439, 2017.

50. Nanayakkara GK, Wang $\mathrm{H}$ and Yang X: Proton leak regulates mitochondrial reactive oxygen species generation in endothelial cell activation and inflammation-A novel concept. Arch Biochem Biophys 662: 68-74, 2019.

51. Rugarli $\mathrm{E}$ and Trifunovic A: Is mitochondrial free radical theory of aging getting old? Biochim Biophys Acta 1847: 1345-1346, 2015.

52. Cheeseman KH and Slater TF: An introduction to free radical biochemistry. Br Med Bull 49: 481-493, 1993.

53. Brieger K, Schiavone S, Miller FJ Jr and Krause KH: Reactive oxygen species: From health to disease. Swiss Med Wkly 142: w13659, 2012.

54. He L, He T, Farrar S, Ji L, Liu T and Ma X: Antioxidants maintain cellular redox homeostasis by elimination of reactive oxygen species. Cell Physiol Biochem 44: 532-553, 2017.

55. Zorov DB, Juhaszova M and Sollott SJ: Mitochondrial reactive oxygen species (ROS) and ROS-induced ROS release. Physiol Rev 94: 909-950, 2014.

56. Vallabh NA,Romano V and Willoughby CE: Mitochondrial dysfunction and oxidative stress in corneal disease. Mitochondrion 36: 103-113, 2017.

57. Panieri E and Santoro MM: ROS homeostasis and metabolism: A dangerous liason in cancer cells. Cell Death Dis 7: e2253, 2016.

58. Loperena R and Harrison DG: Oxidative stress and hypertensive diseases. Med Clin North Am 101: 169-193, 2017.

59. Rani V, Deep G, Singh RK, Palle K and Yadav UC: Oxidative stress and metabolic disorders: Pathogenesis and therapeutic strategies. Life Sci 148: 183-193, 2016.

60. Gerber PA and Rutter GA: The role of oxidative stress and hypoxia in pancreatic beta-cell dysfunction in diabetes mellitus. Antioxid Redox Signal 26: 501-518, 2017.

61. Pramanik KC, Boreddy SR and Srivastava SK: Role of mitochondrial electron transport chain complexes in capsaicin mediated oxidative stress leading to apoptosis in pancreatic cancer cells. PLoS One 6: e20151, 2011.

62. Sena LA and Chandel NS: Physiological roles of mitochondrial reactive oxygen species. Mol Cell 48: 158-167, 2012. 
63. Bugger H, Chen D, Riehle C, Soto J, Theobald HA, Hu XX, Ganesan B, Weimer BC and Abel ED: Tissue-specific remodeling of the mitochondrial proteome in type 1 diabetic akita mice. Diabetes 58: 1986-1997, 2009.

64. Makino A, Scott BT and Dillmann WH: Mitochondrial fragmentation and superoxide anion production in coronary endothelial cells from a mouse model of type 1 diabetes. Diabetologia 53: 1783-1794, 2010

65. Broderick TL: ATP production and TCA activity are stimulated by propionyl-L-carnitine in the diabetic rat heart. Drugs R D 9: 83-91, 2008

66. Anello M, Lupi R, Spampinato D, Piro S, Masini M, Boggi U, Del Prato S, Rabuazzo AM,PurrelloF and Marchetti P: Functional and morphological alterations of mitochondria in pancreatic beta cells from type 2 diabetic patients. Diabetologia 48: 282-289, 2005.

67. Paradies G, Paradies V, Ruggiero FM and Petrosillo G: Oxidative stress, cardiolipin and mitochondrial dysfunction in nonalcoholic fatty liver disease. World J Gastroenterol 20: 14205-14218, 2014.

68. Musatov A, Carroll CA, Liu YC, Henderson GI, Weintraub ST and Robinson NC: Identification of bovine heart cytochrome c oxidase subunits modified by the lipid peroxidation product 4-hydroxy-2-nonenal. Biochemistry 41: 8212-8220, 2002.

69. Sinha K, Das J, Pal PB and Sil PC: Oxidative stress: The mitochondria-dependent and mitochondria-independent pathways of apoptosis. Arch Toxicol 87: 1157-1180, 2013.

70. Molina AJ, Wikstrom JD, Stiles L, Las G, Mohamed H Elorza A, Walzer G, Twig G, Katz S, Corkey BE and Shirihai OS: Mitochondrial networking protects beta-cells from nutrient-induced apoptosis. Diabetes 58: 2303-2315, 2009.

71. Morino K, Petersen KF, Dufour S, Befroy D, Frattini J, Shatzkes N, Neschen S, White MF, Bilz S, Sono S, et al: Reduced mitochondrial density and increased IRS-1 serine phosphorylation in muscle of insulin-resistant offspring of type 2 diabetic parents. J Clin Invest 115: 3587-3593, 2005.

72. Petersen KF, Dufour S, Befroy D, Garcia R and Shulman GI: Impaired mitochondrial activity in the insulin-resistant offspring of patients with type 2 diabetes. N Engl J Med 350: 664-671, 2004.

73. Dan Dunn J, Alvarez LA, Zhang X and Soldati T: Reactive oxygen species and mitochondria: A nexus of cellular homeostasis. Redox Biol 6: 472-485, 2015.

74. Kauppila TES, Kauppila JHK and Larsson NG: Mammalian mitochondria and aging: An update. Cell Metab 25: 57-71, 2017

75. Ye X, Sun X, Starovoytov V and Cai Q: Parkin-mediated mitophagy in mutant hAPP neurons and Alzheimer's disease patient brains. Hum Mol Genet 24: 2938-2951, 2015

76. Fivenson EM, Lautrup S, Sun N, Scheibye-Knudsen M, Stevnsner T, Nilsen H, Bohr VA and Fang EF: Mitophagy in neurodegeneration and aging. Neurochem Int 109: 202-209, 2017.

77. Choi DS, Kim DK, Kim YK and Gho YS: Proteomics, transcriptomics and lipidomics of exosomes and ectosomes. Proteomics 13: 1554-1571, 2013.

78. Alenquer $\mathrm{M}$ and Amorim MJ: Exosome biogenesis, regulation, and function in viral infection. Viruses 7: 5066-5083, 2015

79. Shakeri R, Kheirollahi A and Davoodi J: Apaf-1: Regulation and function in cell death. Biochimie 135: 111-125, 2017.

80. Thorens B: GLUT2, glucose sensing and glucose homeostasis. Diabetologia 58: 221-232, 2015.

81. Nicholls DG: The pancreatic $\beta$-cell: A bioenergetic perspective. Physiol Rev 96: 1385-1447, 2016.

82. Ježek P and Dlasková A: Dynamic of mitochondrial network, cristae, and mitochondrial nucleoids in pancreatic $\beta$-cells. Mitochondrion 49: 245-258, 2019.

83. Mulder H: Transcribing $\beta$-cell mitochondria in health and disease. Mol Metab 6: 1040-1051, 2017.

84. Kwak SH and Park KS: Role of mitochondrial DNA variation in the pathogenesis of diabetes mellitus. Front Biosci (Landmark Ed) 21: 1151-1167, 2016.

85. Jiang Z, Zhang Y, Yan J, Li F, Geng X, Lu H, Wei X, Feng Y, Wang $\mathrm{C}$ and Jia W: De novo mutation of $\mathrm{m} .3243 \mathrm{~A}>\mathrm{G}$ together with m.16093T $>C$ associated with atypical clinical features in a pedigree with MIDD syndrome. J Diabetes Res 2019: 5184647, 2019.

86. Alves D, Calmeiro ME, Macário C and Silva R: Family phenotypic heterogeneity caused by mitochondrial DNA mutation A3243G. Acta Med Port 30: 581-585, 2017.

87. El-Hattab AW, Emrick LT, Hsu JW, Chanprasert S, Jahoor F, Scaglia F and Craigen WJ: Glucose metabolism derangements in adults with the MELAS m.3243A $>\mathrm{G}$ mutation. Mitochondrion 18: 63-69, 2014.
88. Meimaridou E, Goldsworthy M, Chortis V, Fragouli E, Foster PA, Arlt W, Cox R and Metherell LA: NNT is a key regulator of adrenal redox homeostasis and steroidogenesis in male mice. J Endocrinol 236: 13-28, 2018.

89. Santos LRB, Muller C, de Souza AH, Takahashi HK, Spégel P, Sweet IR, Chae H, Mulder H and Jonas JC: NNT reverse mode of operation mediates glucose control of mitochondrial NADPH and glutathione redox state in mouse pancreatic $\beta$-cells. Mol Metab 6: 535-547, 2017.

90. Dutta P, Ma L, Ali Y, Sloot PMA and Zheng J: Boolean network modeling of $\beta$-cell apoptosis and insulin resistance in type 2 diabetes mellitus. BMC Syst Biol 13 (Suppl 2): S36, 2019.

91. Tabebi M, Khabou B, Boukadi H, Ben Hamad M, Ben Rhouma B, Tounsi S, Maalej A, Kamoun H, Keskes-Ammar L, Abid M, et al: Association study of apoptosis gene polymorphisms in mitochondrial diabetes: A potential role in the pathogenicity of MD. Gene 639: 18-26, 2018.

92.Zhang J, Liu Y, Yang HW, Xu HY and Meng Y: Molecular mechanism of beta cell apoptosis induced by p58 in high glucose medium. Sheng Li Xue Bao 61: 379-385, 2009 (In Chinese).

93. Han J, Song B, Kim J, Kodali VK, Pottekat A, Wang M, Hassler J, Wang S, Pennathur S, Back SH, et al: Antioxidants complement the requirement for protein chaperone function to maintain $\beta$-cell function and glucose homeostasis. Diabetes 64: 2892-2904, 2015.

94. Vozza A, Parisi G, De Leonardis F, Lasorsa FM, Castegna A, Amorese D, Marmo R, Calcagnile VM, Palmieri L, Ricquier D, et al: UCP2 transports C4 metabolites out of mitochondria, regulating glucose and glutamine oxidation. Proc Natl Acad Sci USA 111: 960-965, 2014.

95. Collins S, Pi J and Yehuda-Shnaidman E: Uncoupling and reactive oxygen species (ROS)-a double-edged sword for $\beta$-cell function? 'Moderation in all things'. Best Pract Res Clin Endocrinol Metab 26: 753-758, 2012.

96. Emre Y, Hurtaud C, Karaca M, Nubel T, Zavala F and Ricquier D: Role of uncoupling protein UCP2 in cell-mediated immunity: How macrophage-mediated insulitis is accelerated in a model of autoimmune diabetes. Proc Natl Acad Sci USA 104: 19085-19090, 2007

97. Lee SC, Robson-Doucette CA and Wheeler MB: Uncoupling protein 2 regulates reactive oxygen species formation in islets and influences susceptibility to diabetogenic action of streptozotocin. J Endocrinol 203: 33-43, 2009.

98. Sharoyko VV, Abels M, Sun J, Nicholas LM, Mollet IG, Stamenkovic JA, Göhring I, Malmgren S, Storm P, Fadista J, et al: Loss of TFB1M results in mitochondrial dysfunction that leads to impaired insulin secretion and diabetes. Hum Mol Genet 23: 5733-5749, 2014

99. Nicholas LM, Valtat B, Medina A, Andersson L, Abels M, Mollet IG, Jain D, Eliasson L, Wierup N, Fex M and Mulder H: Mitochondrial transcription factor B2 is essential for mitochondrial and cellular function in pancreatic $\beta$-cells. Mol Metab 6: 651-663, 2017.

100. Baixauli F, López-Otín C and Mittelbrunn M: Exosomes and autophagy: Coordinated mechanisms for the maintenance of cellular fitness. Front Immunol 5: 403, 2014.

101. Wong SK, Chin KY, Suhaimi FH, Ahmad F and Ima-Nirwana S: The effects of a modified high-carbohydrate high-fat diet on metabolic syndrome parameters in male rats. Exp Clin Endocrinol Diabetes 126: 205-212, 2018.

102. Rutter GA, Pullen TJ, Hodson DJ and Martinez-Sanchez A: Pancreatic $\beta$-cell identity, glucose sensing and the control of insulin secretion. Biochem J 466: 203-218, 2015.

103. Newsholme P, Cruzat VF, Keane KN, Carlessi R and de Bittencourt PI Jr: Molecular mechanisms of ROS production and oxidative stress in diabetes. Biochem J 473: 4527-4550, 2016.

104. Rehman K and Akash MSH: Mechanism of generation of oxidative stress and pathophysiology of type 2 diabetes mellitus: How are they interlinked? J Cell Biochem 118: 3577-3585, 2017.

105. Rharass T, Lemcke H, Lantow M, Kuznetsov SA, Weiss DG and Panáková D: Ca2+-mediated mitochondrial reactive oxygen species metabolism augments Wnt/beta-catenin pathway activation to facilitate cell differentiation. J Biol Chem 289 27937-27951, 2014

106. Sarre A, Gabrielli J, Vial G, Leverve XM and AssimacopoulosJeannet F: Reactive oxygen species are produced at low glucose and contribute to the activation of AMPK in insulin-secreting cells. Free Radic Biol Med 52: 142-150, 2012. 
107. Furukawa S, Fujita T, Shimabukuro M, Iwaki M, Yamada Y, Nakajima Y, Nakayama O, Makishima M, Matsuda M and Shimomura I: Increased oxidative stress in obesity and its impact on metabolic syndrome. J Clin Invest 114: 1752-1761, 2004.

108. Nowotny K, Jung T, Höhn A, Weber D and Grune T: Advanced glycation end products and oxidative stress in type 2 diabetes mellitus. Biomolecules 5: 194-222, 2015.

109. Turrens JF: Mitochondrial formation of reactive oxygen species. J Physiol 552: 335-344, 2003.

110. Wang $J$ and Wang $\mathrm{H}$ : Oxidative stress in pancreatic beta cell regeneration. Oxid Med Cell Longev 2017: 1930261, 2017.

111. Ivarsson R, Quintens R, Dejonghe $S$, Tsukamoto $K$, in 't Veld $P$, Renström E and Schuit FC: Redox control of exocytosis: Regulatory role of NADPH, thioredoxin, and glutaredoxin. Diabetes 54: 2132-2142, 2005.

112. Hopps E, Noto D, Caimi G and Averna MR: A novel component of the metabolic syndrome: The oxidative stress. Nutr Metab Cardiovasc Dis 20: 72-77, 2010 .

113. Rao R: Oxidative stress-induced disruption of epithelial and endothelial tight junctions. Front Biosci 13: 7210-7226, 2008.

114. Newsholme P, Rebelato E, Abdulkader F, Krause M, Carpinelli A and Curi R: Reactive oxygen and nitrogen species generation, antioxidant defenses, and $\beta$-cell function: A critical role for amino acids. J Endocrinol 214: 11-20, 2012.

115. Fiorentino TV, Prioletta A, Zuo P and Folli F: Hyperglycemiainduced oxidative stress and its role in diabetes mellitus related cardiovascular diseases. Curr Pharm Des 19: 5695-5703, 2013.

116. Koehler A and Van Noorden CJ: Reduced nicotinamide adenine dinucleotide phosphate and the higher incidence of pollution-induced liver cancer in female flounder. Environ Toxicol Chem 22: 2703-2710, 2003.

117. Baldewpersad Tewarie NM, Burgers IA, Dawood Y, den Boon HC, den Brok MG, Klunder JH, Koopmans KB Rademaker E, van den Broek HB, van den Bersselaar SM, et al: $\mathrm{NADP}^{+}$-dependent IDH1 R132 mutation and its relevance for glioma patient survival. Med Hypotheses 80: 728-731, 2013.

118. Atai NA, Renkema-Mills NA, Bosman J, Schmidt N, Rijkeboer D, Tigchelaar W, Bosch KS, Troost D, Jonker A, Bleeker FE, et al: Differential activity of NADPH-producing dehydrogenases renders rodents unsuitable models to study IDH1R132 mutation effects in human glioblastoma. J Histochem Cytochem 59: 489-503, 2011

119. Pan HC, Lee CC, Chou KM, Lu SC and Sun CY: Serum levels of uncoupling proteins in patients with differential insulin resistance: A community-based cohort study. Medicine (Baltimore) 96: e8053, 2017.

120. Brondani LA, Assmann TS, Duarte GC, Gross JL, Canani LH and Crispim D: The role of the uncoupling protein 1 (UCP1) on the development of obesity and type 2 diabetes mellitus. Arq Bras Endocrinol Metabol 56: 215-225, 2012

121. Oelkrug R, Goetze N, Meyer CW and Jastroch M: Antioxidant properties of UCP1 are evolutionarily conserved in mammals and buffer mitochondrial reactive oxygen species. Free Radic Biol Med 77: 210-216, 2014.

122. Sreedhar A and Zhao Y: Uncoupling protein 2 and metabolic diseases. Mitochondrion 34: 135-140, 2017.

123. Li N, Karaca M and Maechler P: Upregulation of UCP2 in beta-cells confers partial protection against both oxidative stress and glucotoxicity. Redox Biol 13: 541-549, 2017.

124. Senese R, Valli V, Moreno M, Lombardi A, Busiello RA, Cioffi F, Silvestri E, Goglia F, Lanni A and de Lange P: Uncoupling protein 3 expression levels influence insulin sensitivity, fatty acid oxidation, and related signaling pathways. Pflugers Arch 461: 153-164, 2011.

125. Edwards KS, Ashraf S, Lomax TM, Wiseman JM, Hall ME, Gava FN, Hall JE, Hosler JP and Harmancey R: Uncoupling protein 3 deficiency impairs myocardial fatty acid oxidation and contractile recovery following ischemia/reperfusion. Basic Res Cardiol 113: 47, 2018

126. Chan CB and Harper ME: Uncoupling proteins: Role in insulin resistance and insulin insufficiency. Curr Diabetes Rev 2: 271-283, 2006.

127. Jena NR: DNA damage by reactive species: Mechanisms, mutation and repair. J Biosci 37: 503-517, 2012.
128. Borchert A, Kalms J, Roth SR, Rademacher M, Schmidt A, Holzhutter HG, Kuhn H and Scheerer P: Crystal structure and functional characterization of selenocysteine-containing glutathione peroxidase 4 suggests an alternative mechanism of peroxide reduction. Biochim Biophys Acta Mol Cell Biol Lipids 1863: 1095-1107, 2018.

129. Jung $\mathrm{CH}$ and Choi KM: Impact of high-carbohydrate diet on metabolic parameters in patients with type 2 diabetes. Nutrients 9: 322, 2017.

130. Li C, Deng X, Xie X, Liu Y, Friedmann Angeli JP and Lai L: Activation of glutathione peroxidase 4 as a novel anti-inflammatory strategy. Front Pharmacol 9: 1120, 2018.

131. Lillig $\mathrm{CH}$ and Holmgren A: Thioredoxin and related molecules-from biology to health and disease. Antioxid Redox Signal 9: 25-47, 2007.

132. Eguchi $\mathrm{K}$ and Nagai R: Islet inflammation in type 2 diabetes and physiology. J Clin Invest 127: 14-23, 2017.

133. Margaryan S, Witkowicz A, Partyka A, Yepiskoposyan L, Manukyan G and Karabon L: The mRNA expression levels of uncoupling proteins 1 and 2 in mononuclear cells from patients with metabolic disorders: Obesity and type 2 diabetes mellitus. Postepy Hig Med Dosw (Online) 71: 895-900, 2017.

134. Dalmas E, Venteclef N, Caer C, Poitou C, Cremer I, Aron-Wisnewsky J, Lacroix-Desmazes S, Bayry J, Kaveri SV, Clément K, et al: T cell-derived IL-22 amplifies IL-1 $\beta$-driven inflammation in human adipose tissue: Relevance to obesity and type 2 diabetes. Diabetes 63: 1966-1977, 2014.

135. Oh H, Park SH, Kang MK, Kim YH, Lee EJ, Kim DY, Kim SI, Oh S, Lim SS and Kang YH: Asaronic acid attenuates macrophage activation toward M1 phenotype through inhibition of NF- $\kappa$ B pathway and JAK-STAT signaling in glucose-loaded murine macrophages. J Agric Food Chem, 2019.

136. Wang Y, Shan B, Liang Y, Wei H and Yuan J: Parkin regulates NF- $\mathrm{BB}$ by mediating site-specific ubiquitination of RIPK1. Cell Death Dis 9: 732, 2018

137. Kim DH, Lee JC, Kim S, Oh SH, Lee MK, Kim KW and Lee MS: Inhibition of autoimmune diabetes by TLR2 tolerance. J Immunol 187: 5211-5220, 2011.

138. Tan Q, Majewska-Szczepanik M, Zhang X, Szczepanik M, Zhou Z, Wong FS and Wen L: IRAK-M deficiency promotes the development of type 1 diabetes in NOD mice. Diabetes 63: 2761-2775, 2014.

139. QiNan W, XiaGuang G, XiaoTian L, WuQuan D, Ling Z and Bing C: Par-4/NF- $\mathrm{BB}$ mediates the apoptosis of islet $\beta$ cells induced by glucolipotoxicity. J Diabetes Res 2016: 4692478, 2016.

140. Cnop M, Toivonen S, Igoillo-Esteve M and Salpea P: Endoplasmic reticulum stress and eIF2 $\alpha$ phosphorylation: The Achilles heel of pancreatic $\beta$ cells. Mol Metab 6: 1024-1039, 2017.

141. Sauter NS, Thienel C, Plutino Y, Kampe K, Dror E, Traub S, Timper K, Bédat B, Pattou F, Kerr-Conte J, et al: Angiotensin II induces interleukin-1 $\beta$-mediated islet inflammation and $\beta$-cell dysfunction independently of vasoconstrictive effects. Diabetes 64: 1273-1283, 2015.

142. Dinarello CA, Donath MY and Mandrup-Poulsen T: Role of IL-1beta in type 2 diabetes. Curr Opin Endocrinol Diabetes Obes 17: 314-321, 2010.

143. Carrasco-Pozo C, Tan KN, Gotteland M and Borges K: Sulforaphane protects against high cholesterol-induced mitochondrial bioenergetics impairments, inflammation, and oxidative stress and preserves pancreatic $\beta$-cells function. Oxid Med Cell Longev 2017: 3839756, 2017.

144. Donath MY and Shoelson SE: Type 2 diabetes as an inflammatory disease. Nat Rev Immunol 11: 98-107, 2011.

145. Gomes BF and Accardo CM: Immunoinflammatory mediators in the pathogenesis of diabetes mellitus. Einstein (Sao Paulo) 17: eRB4596, 2019 (In En, Portuguese).

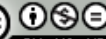

This work is licensed under a Creative Commons Attribution-NonCommercial-NoDerivatives 4.0 International (CC BY-NC-ND 4.0) License. 